\title{
NEW ESTIMATIONS OF THE SOLUTIONS OF MULTIDIMENSIONAL INTEGRAL INEQUALITIES
}

\author{
ICE B. RISTESKI AND KOSTADIN G. TRENČEVSKI
}

Abstract. In this paper new general estimations of integral inequalities of Volterra's type as some special estimations based on the Bessel function are given.

Mathematics subject classification (2000): 49A29, 45D05.

Key words and phrases: Integral inequalities, integral inequations of Volterra's type, Bessel function, Bellman-Gronwall lemma.

\section{REFERENCES}

[1] E. F. Beckenbach and R. Bellman, Inequalities, Berlin - Heidelberg - New York, 1971.

[2] J. Chandra AND B. A. Fleishman, On a Generalization of the Gronwall-Bellman Lemma in Partially Ordered Banach Spaces, J. Math. Anal. Appl. 31 (1970), 668-681.

[3] H. M. SALPAGAROV, Integral Inequalities with Operators of Volterra Type, DAN SSSR (in Russian) 177 (1967), 277-280. 